Research Article

\title{
Construction and Optimization Analysis of Network Knowledge Community Based on System Dynamics
}

\author{
Yu Zhenlei iD ${ }^{1,2}$ and Guo Chunxia ${ }^{3}$ \\ ${ }^{1}$ School of Management, Shandong University, Jinan, China \\ ${ }^{2}$ Information Ministry of Library, QiLu University of Technology (Shandong Academy of Sciences), Jinan, China \\ ${ }^{3}$ Information Ministry of Library, Binzhou University, Binzhou, China \\ Correspondence should be addressed to Yu Zhenlei; m5172@163.com
}

Received 17 April 2020; Revised 10 June 2020; Accepted 18 June 2020; Published 4 August 2020

Guest Editor: Miaojuan Peng

Copyright (C) $2020 \mathrm{Yu}$ Zhenlei and Guo Chunxia. This is an open access article distributed under the Creative Commons Attribution License, which permits unrestricted use, distribution, and reproduction in any medium, provided the original work is properly cited.

\begin{abstract}
In this study, an evolutionary game model of the collaboration between the government and network knowledge community investors is constructed to address the problems of insufficient scale development of the network knowledge community and inconsistent internal mechanism. This model assists in determining the most appropriate internal mechanism for the development of the network knowledge community. The evolutionary game model, based on the system dynamic model fitting analysis, showed that the government and investors adopting positive strategy at the same time is for the optimal strategy. Promoting the network knowledge community construction is the key to improve the initial probability of both sides to take the active strategy, reducing the threshold of evolution.
\end{abstract}

\section{Introduction}

Fei Xiaotong first defined community as a “社区" in the early 1930 s, and this definition has been used by scholars to this day in China. In 1993, Rheingold proposed the concept of a "virtual community." WEEL, a global electronic discussion chain founded by Brand and Brilliant, is considered the origin of online communities, and it has since become the most important platform for online communication and interaction. There are 24 articles on the theme of "network knowledge community" in the China National Knowledge Infrastructure till now. In 2007, Wang elaborated the principle of the open network knowledge community of library 2.0 and its function realization [1]. Chen Hongqin further defined the knowledge dissemination mechanism of the library network knowledge community as knowledge construction, knowledge transfer and sharing, knowledge innovation, and knowledge service mechanism [2]. From the network knowledge community, Chen built a three-dimensional structure based on the network knowledge community user behaviour initiation model [3]. Du pointed out that the small world network easily facilitates the dissemination of knowledge, improves the knowledge transfer ability, and accelerates the growth rate of knowledge [4].

Some international literature studies wrote that the Wikipedia was one of the largest and best-known network knowledge communities. Researches often used social network analysis applied to networks created based on behavioral data available from the edit history of the Wikipedia [5]. More literature studies use virtual communities to replace the concept of networked knowledge communities. Virtual communities (VCs) bring together geographically dispersed, like-minded people to form a network for knowledge exchange. To promote knowledge sharing, it is important to know why individuals choose to give or receive knowledge with other community members [6]. Since 1996, some people have been studying this problem, and the trend is increasing year by year. In recent years, the average amount of published papers is about 260. The research mainly focuses on the internal mechanism of the community, but there is little research on the simulation model of the possibility of community construction. 
Effective operations of knowledge community require the coordination of distributed knowledge. Many companies have created internal network knowledge communities, in which employees can exchange solutions in various knowledge domains anywhere in the world [7]. Network knowledge communities offer an exciting potential to effectively mobilize knowledge across locations and expertise, but little is known about how to build communities easily. The purpose of this study is to provide us with a general model for establishing the network knowledge community by means of simulation.

These studies have laid a theoretical foundation of the complex knowledge dissemination system of a network knowledge community, thereby providing a point of reference for applying this concept. However, such a system cannot effectively reproduce a consistent internal mechanism required to build a strong network knowledge community. To build such a community, the influencing factors and interaction mechanism are typically complex. Qualitative research conducted on a dynamic construction system has been limited; further, limited analytical simulations have been applied in relevant research. At present, the funds available for further construction of the network knowledge community are insufficient. Moreover, the required standard of construction is unclear [8], and the incentive policy needs to be improved. Hence, there is a need to study both government and construction sides to build a strong network knowledge community and establish a consistent internal mechanism. Based on the government and stakeholders of the network knowledge community [9], this study aims to build a simulation model for the participants and investigate each critical variable in the system to establish an optimal path for improving the efficiency.

\section{Building an Evolutionary Model of the Government and Investors' Decision Behaviour of the Network Knowledge Community}

2.1. Model Hypothesis. In the process of constructing the network knowledge community, the main participants include the government, the investors of the network knowledge community, and the users of the network knowledge community [10-12]. During the game, the participants begin by declaring their own interests and select the strategy that is most beneficial to them. The selection of each party's strategy is critical, and it may be used to interact with each other to form a dynamic relationship between the participants [13]. The main objective of this study is to analyse the dynamics between the government and investors in the network knowledge community [14]. Among them, the government must choose two strategies (using an incentive policy for the construction of a network knowledge community and not using an incentive policy for such construction) and the investor must choose two strategies (build the network knowledge community or not build it). In addition, the probability that an investor will choose to invest in a network knowledge community is $\alpha$, and the probability that the government will adopt an incentive policy for a network knowledge community is $\beta[15,16]$. Both parties constitute people with limited rational economic influence who select their strategies based on the existing conditions and lack the ability to predict situations, but possess the ability to judge the subsequent effects. The variables and their economic meanings are shown in Table 1 [17].

For the above variable hypothesis, $a_{2}+a_{3}>b_{1}$ should be satisfied [18]; that is, the sum of the benefits gained by the investor in the construction of the network knowledge community should be greater than the extra cost of the construction of the network knowledge community $[19,20]$. According to the above assumptions and related deductive game theory, the government and the investor's game payment matrix is shown in Table 2.

When the government adopts the incentive strategy $\beta$, the investor's expected return is $E c_{1}$; when the government adopts the incentive strategy $1-\beta$, the investor's expected return is $E c_{2}$. When investors adopt a no-build strategy, the government's expected revenue is $E z_{2}$; when investors build online knowledge communities, governments expected benefit is $E z_{1}[18,19]$. By definition, the government is not independent of each other while playing games with investors. Each investor's strategy is chosen not only to take into account the government's strategic choices, but also to be influenced by other investor strategies, as well as by the government.

2.2. Replication of Dynamic Equation of Each Party in the Game. According to the game payoff matrix, the expected benefits of investors in building or not building the network knowledge community are as follows [17]:

$$
\begin{aligned}
& E c_{1}=\beta\left(c_{1}+c_{2}+c_{3}-b_{1}\right)+(1-\beta)\left(c_{1}+c_{3}-b_{1}\right), \\
& E c_{2}=\beta\left(c_{1}-b_{2}\right)+(1-\beta) c_{1} .
\end{aligned}
$$

Investors' average expected returns:

$$
\overline{\mathrm{Ec}}=\alpha E c_{1}+(1-\alpha) E c_{2} .
$$

According to the evolutionary game principle, the rate of proportional change of the investor's strategy, that is, the investor's replicated dynamic equation, is

$$
\begin{aligned}
F(\alpha) & =\frac{\partial \alpha}{\partial t}=\alpha\left(E c_{1}-\overline{E c}\right)=\alpha(1-\alpha)\left(E c_{1}-E c_{2}\right) \\
& =\alpha(1-\alpha)\left(\beta c_{2}+\beta b_{2}+c_{3}-b_{1}\right) .
\end{aligned}
$$

In the same way, according to the game payoff matrix, government's expected returns to the network knowledge community with or without incentive policies are

$$
\begin{aligned}
& E z_{1}=\alpha\left(c_{1}+c_{3}-b_{3}-b_{4}\right)+(1-\alpha)\left(c_{1}-b_{4}\right), \\
& E z_{2}=\alpha\left(c_{1}+c_{2}\right)+(1-\alpha) c_{1} .
\end{aligned}
$$

Government average expected return is 
TABle 1: The variables and their economic meanings.

\begin{tabular}{lc}
\hline Variable & Economic meanings \\
\hline$a_{1}$ & The normal earnings of investors in building traditional intellectual products \\
$a_{2}$ & Government incentive policy conditions, incentive gains from investors building network knowledge communities \\
$a_{3}$ & Intangible additional benefits that investors get when building network knowledge communities \\
$b_{1}$ & The more cost of building a network knowledge community than building traditional intellectual products \\
$b_{2}$ & The government incentive policies, punishment caused by investors not building network knowledge communities \\
$c_{1}$ & The normal benefits when government does not adopt incentive policies for network knowledge communities \\
$c_{2}$ & Government without incentives, investors are still choosing to build network knowledge community, the government's extra \\
$c_{3}$ & Government incentives, additional benefits to government when investors choose to build network knowledge communities \\
$b_{3}$ & The cost of subsidies and tax incentives paid by the government for incentives for the network knowledge community \\
$b_{4}$ & The cost of policy formulation, publicity, etc., paid by the government when adopting incentive policies for community \\
\hline
\end{tabular}

TABle 2: Payment matrix of government and investor.

\begin{tabular}{lcc}
\hline Game players & Adopting incentives $\beta$ & Government \\
\hline Construction $\alpha$ & $c_{1}+c_{2}+c_{3}-b_{1}, a_{1}+a_{3}-b_{3}-b_{4}$ & No incentive policy $(1-\beta)$ \\
No construction $(1-\alpha)$ & $c_{1}-b_{2}, a_{1}-b_{4}$ & $c_{1}+c_{3}-b_{1} a_{1}+a_{2}$ \\
$c_{1}, a_{1}$ & $c_{1}$ \\
\hline
\end{tabular}

$$
\overline{E z}=\beta E c_{1}+(1-\beta) E c_{2} .
$$

According to the evolutionary game principle, the rate of change of the investor's strategy, i.e., the government's replicated dynamic equation, is as follows:

$$
\begin{aligned}
F(\beta) & =\frac{\partial \beta}{\partial x}=\beta\left(E_{1}-\overline{E z}\right)=\beta(1-\beta)\left(E_{1}-E z_{2}\right) \\
& =\beta(1-\beta)\left[\alpha\left(z_{3}-z_{2}-b_{3}\right)-b_{4}\right] .
\end{aligned}
$$

2.3. Analysis of Evolutionary Game Models. In the game, regardless of what strategy each party selects, one party will select a certain strategy that is called the dominant strategy. If the combination of strategies of the two players in a game constitutes their respective dominant strategies, the combination is defined as the Nash equilibrium. The generalized Nash equilibrium is not considered the optimal allocation of social resources nor does it have a certain payment function $[21,22]$.

Using formulae (1)-(3) available to $F(\alpha)=0$, to calculate all the replicated dynamic stable states, we obtain two steady states, $\alpha^{*}=0$ and $\alpha^{*}=1$. If $\beta=\beta^{*}=\left(\left(b_{1}-a_{3}\right) / a_{2}-b_{2}\right)$, we obtain $F(\alpha)=0$, which is a stable state for any $\alpha$. If $\beta<\beta^{*}$, $\alpha=0$ is an evolutionary stability strategy; and if $\beta>\beta^{*}, \alpha=1$ is an evolutionary stability strategy $[23,24]$.

Similarly, when $F(\beta)=0$, to calculate the replicated dynamic stable state, we obtain two steady states, $\beta^{*}=0$ and $\beta^{*}=1$. If $\alpha<\alpha^{*}=\left(b_{3} /\left(c_{3}-c_{2}-b_{3}\right)\right)$, we obtain $F(\beta)=0$, a stable state for any player. If $\alpha<\alpha^{*}, \beta=0$ is an evolutionary stability strategy; and if $\alpha>\alpha^{*}, \beta=1$ is an evolutionary stability strategy $[25,26]$.

\section{The Equilibrium Point in the Evolutional Process and Its Stability Analysis}

3.1. System Dynamic (SD) Model Construction. In order to further study the process of game evolution between the government and investors in the process of promoting the network knowledge community, based on the principles of evolutionary game and system dynamics, this paper build an evolutionary game simulation model with the Vensim DSS software.

The variables involved in the model are 2 horizontal variables (see $\beta$ and $\alpha$ in Figure 1), namely, the probability $\alpha$ that the investor chooses to build the network knowledge community and the probability $\beta$ that the government chooses to adopt the incentive policy. Four auxiliary variables are used: $E c_{1}, E c_{2}, E z_{1}$, and $E z_{2}$; there are two rate variables, $F(\alpha)$ and $F(b)$, which represent the derivative with respect to time of the proportion of each party's strategies. And, constants $a_{1}, a_{2}, a_{3}, c_{1}, c_{2}, c_{3}, b_{1}, b_{2}, b_{3}$, and $b_{4}$ are used. According to the function relationship of the pretext (1) to the type (8) and the causal relationship between the variables, a stock flowchart of the evolutionary game can be obtained. The constants in the model can be assigned to simulate the model as shown in Figure 1.

3.2. Evolutionary Game Simulation Based on System Dynamics. In the actual game process, the strategy selection of both parties is random. The preconditions of the above formula and the payment matrix are assigned as follows: $a 1=8, a 2=4, a 3=1.5, c 1=10, c 2=1, c 3=6, b 1=4, b 2=1$, $b 3=3$, and $b 4=1$; then, from the above initial value and threshold value calculation formula, $\beta^{*}=\alpha^{*}=0.5$. Therefore, 


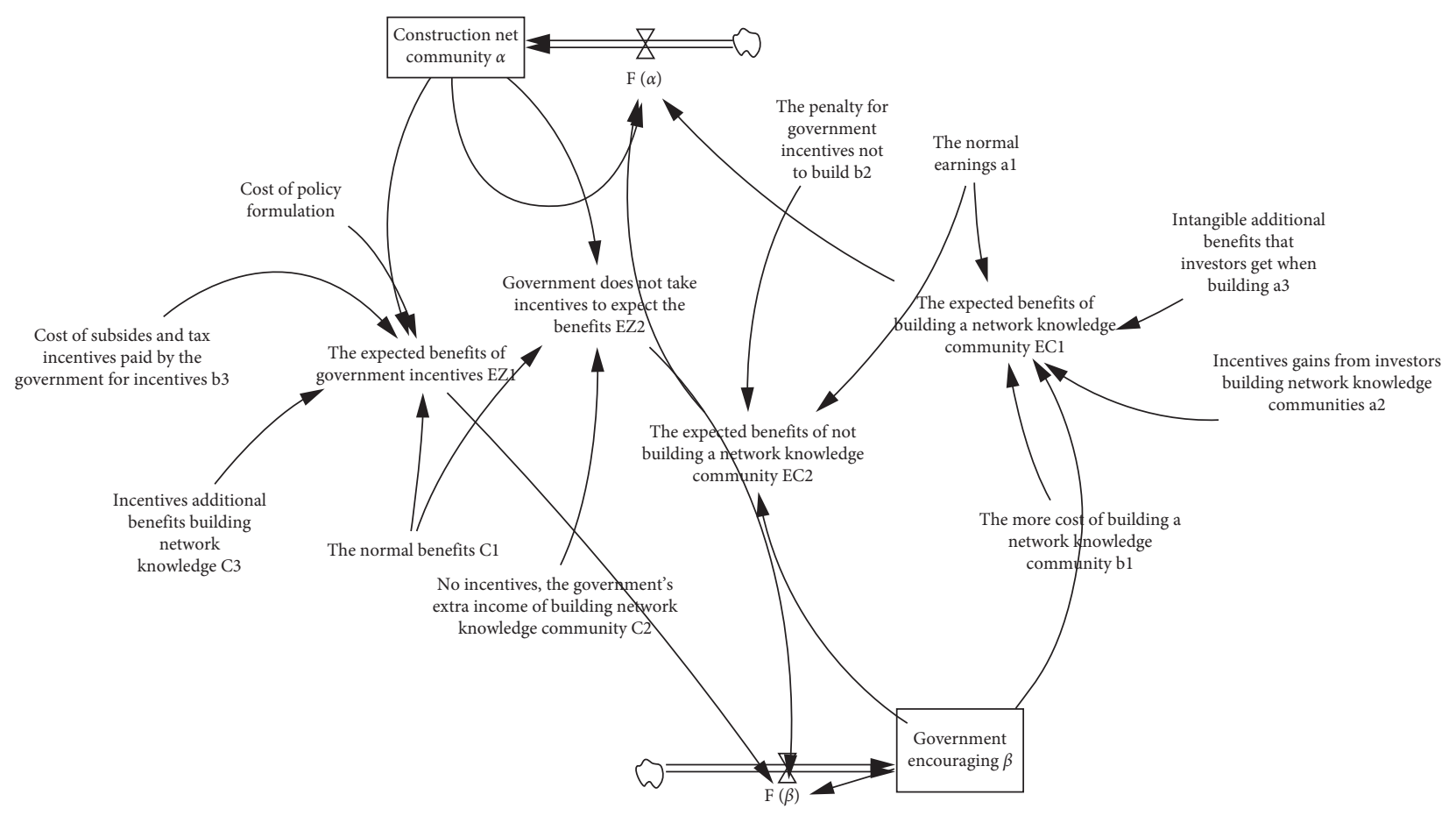

FIgURE 1: System dynamics model.

each stable evolutionary strategy in the set is theoretically obtained as the initial state value. Vensim DSS software is used to set the preliminary value, where the initial time is 0 and the end time is 10. First, a "week" is applied as the unit of time.

As shown in Figure 2(a), using a "week" as the unit of time, $\alpha$ fluctuates significantly, and a stable state is not observed for 10 weeks. As shown in Figure 2(b), when the unit of time is changed to a "month," $\alpha$ exhibits a relatively stable trend. However, there is still a fluctuation at time 0 . In addition, the equilibrium point $(1,0)$ is not an ESS. When $a_{2}+a_{3}>b_{1}$, the variable meets the payment matrix condition, and the four curves are unstable. Therefore, nno investment in the construction of a network knowledge community, no incentive policy\} is not an ESS.

Hypothesis 1. Evolutionary analysis of the equilibrium point $(1,0)$.

When the probability of the construction is greater than that of the threshold and the probability of the government is less than that of the threshold, that is $\alpha=0.8$ and $\beta=0.3$, the stable point of the evolution of the last interaction behaviours that can be obtained using the model simulation is 0 . That is, \{Build network knowledge community, No incentive policy\} is an evolutionary stability strategy (ESS). However, the evolution of the government incentive probability stock fluctuates significantly, and the regression time is relatively longer. The reason for this could be that the initial probability of the policy side is small, and it takes a considerable amount of time for the system to learn and adjust. At the same time, the investors will maintain a "wait-and-see attitude" towards the government that will ultimately affect the operation time of the entire system.
Hypothesis 2. Evolutionary analysis of the equilibrium point $(0,1)$.

When the probability of the construction is less than that of the threshold and the probability of the government is greater than that of the threshold, that is $\alpha=0.3$ and $\beta=0.8$, the stable point of the evolution of the last interaction behaviours that can be obtained by the model simulation is 0 . That is, No building network knowledge community, Incentive policy\} is an evolutionary stability strategy (ESS). Moreover, there is a system for learning and adjusting time too, but time of the equilibrium point system in Figure 3 is longer than that in Figure 4 because the investor in the system is the dominant party in the strategy.

Hypothesis 3. Evolutionary analysis of the equilibrium point $(1,1)$.

This study expands the time period in Figure 3 by 1.5 times for further simulation analysis (see Figure 5), and thus making it easier to obtain a stable curve when adjusting the variables in the range of values. When investors choose to build a network knowledge community with a probability slightly greater than $\alpha^{*}(0.5)$ and the government adopts an incentive policy for the network knowledge community with a probability slightly greater than $\beta^{*}(0.5)$, that is, $\alpha=0.6=\beta$, the system will eventually converge to 1 . That is, Building the network knowledge community, Incentive policy\} is an evolutionary stability strategy (ESS). The system is likely to achieve Pareto's optimal value when at least one of the initial values of both sides of the game is greater than that of the threshold. Therefore, the threshold values of both sides, which include the probability of the investor building the network knowledge community and the probability of the government incentive policy in the system, are the key to influencing the evolution results. 


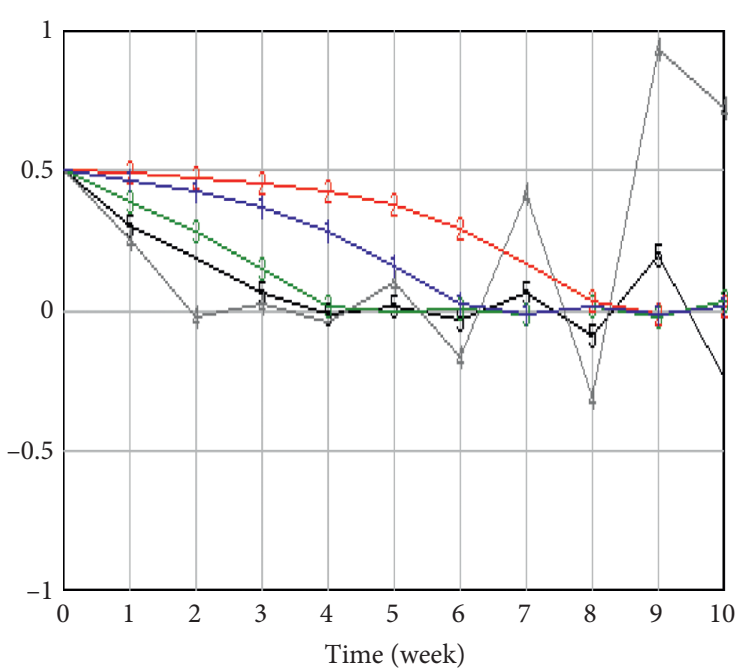

$1-\mathrm{a} 3=1.9 \mathrm{~b} 3=0.9$

$-2 \mathrm{a} 3=1.6 \mathrm{~b} 3=0.9$

$-3-\mathrm{a} 3=2 \mathrm{a} 2=3.2$

(a)

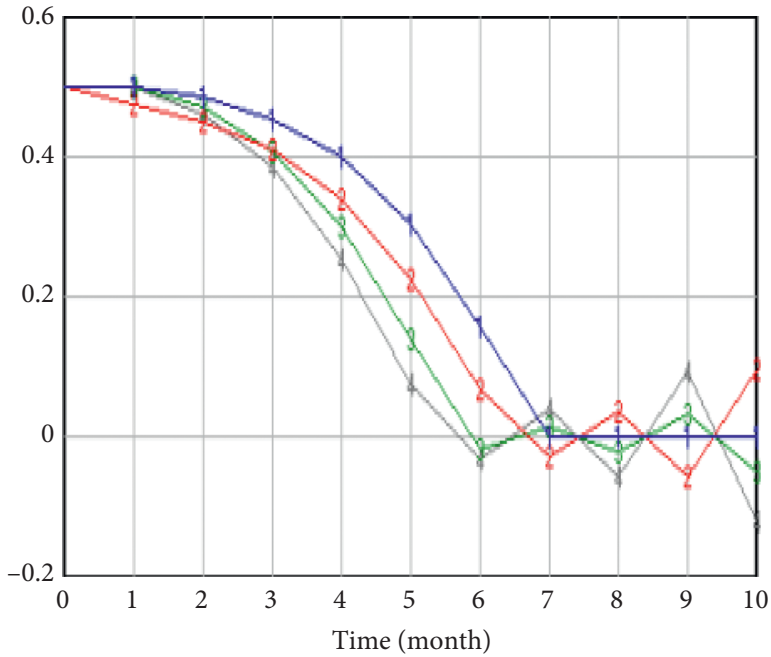

$1-\mathrm{a} 3=1.5 \mathrm{~b} 1=4 \mathrm{c} 2=1 \quad 3-\mathrm{b} 4=1 \mathrm{~b} 3=3$

$-2 \mathrm{a} 3=1.5 \mathrm{~b} 1=4 \mathrm{c} 3=6 \quad-\mathrm{b} 4=1.1 \mathrm{~b} 3=3$

(b)

Figure 2: Initial state adjustment. (a) Construction net community $\alpha$. (b) Construction net community $\alpha$.

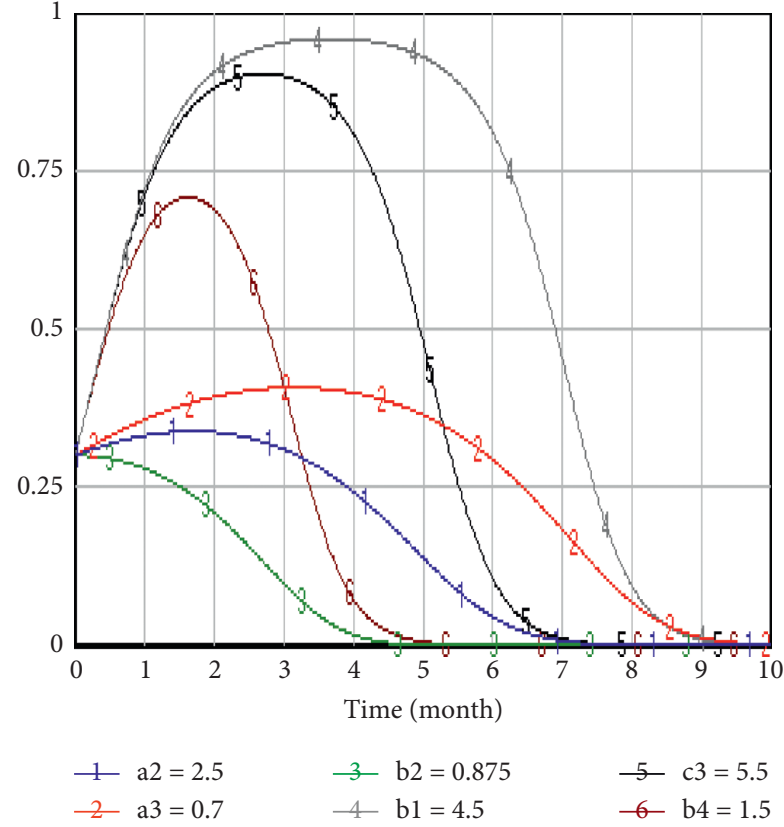

(a)

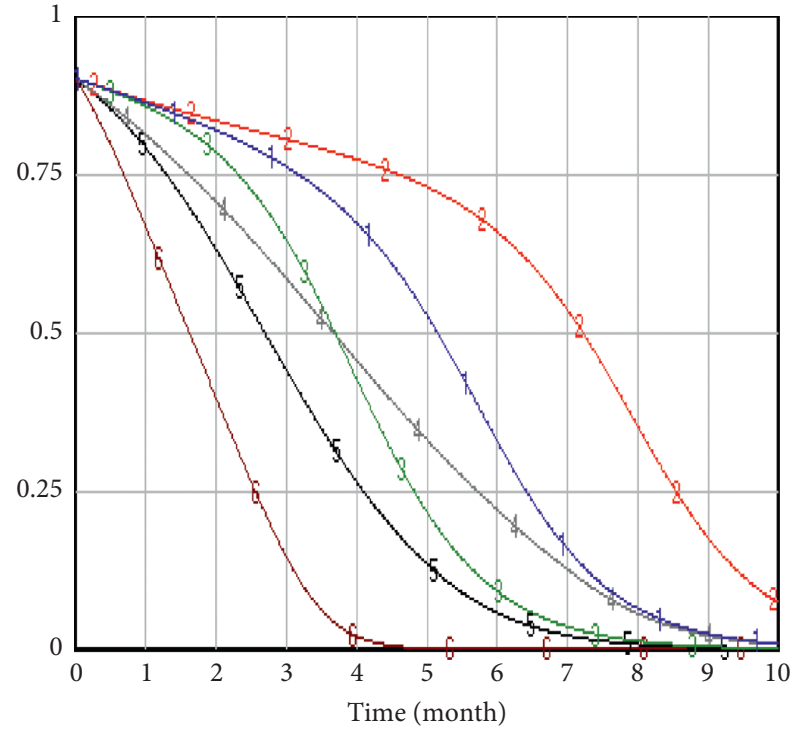

$$
\begin{array}{ll}
1- & \mathrm{a} 2=2.5 \\
-2 & \mathrm{a} 3=0.7
\end{array}
$$$$
\begin{aligned}
& -3-\mathrm{b} 2=0.875 \\
& -\mathrm{b} 1=4.5
\end{aligned}
$$$$
\text { 5- c3 }=5.5
$$

(b)

FIGURE 3: Simulation results of the local stability at point F $(0,1)$ under different conditions. (a) Construction net community $\alpha$. (b) Government encouraging $\beta$. 


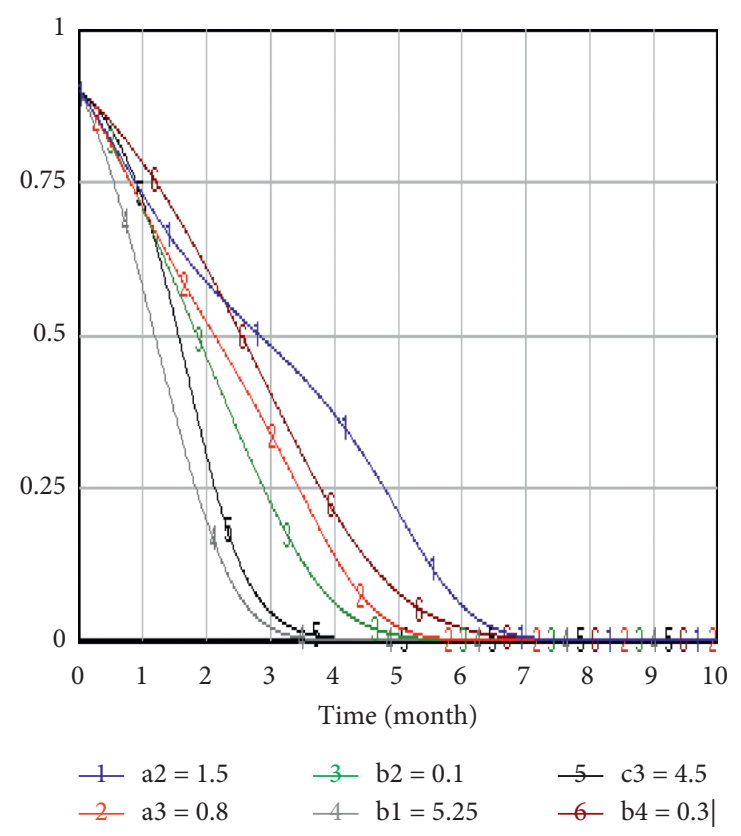

(a)

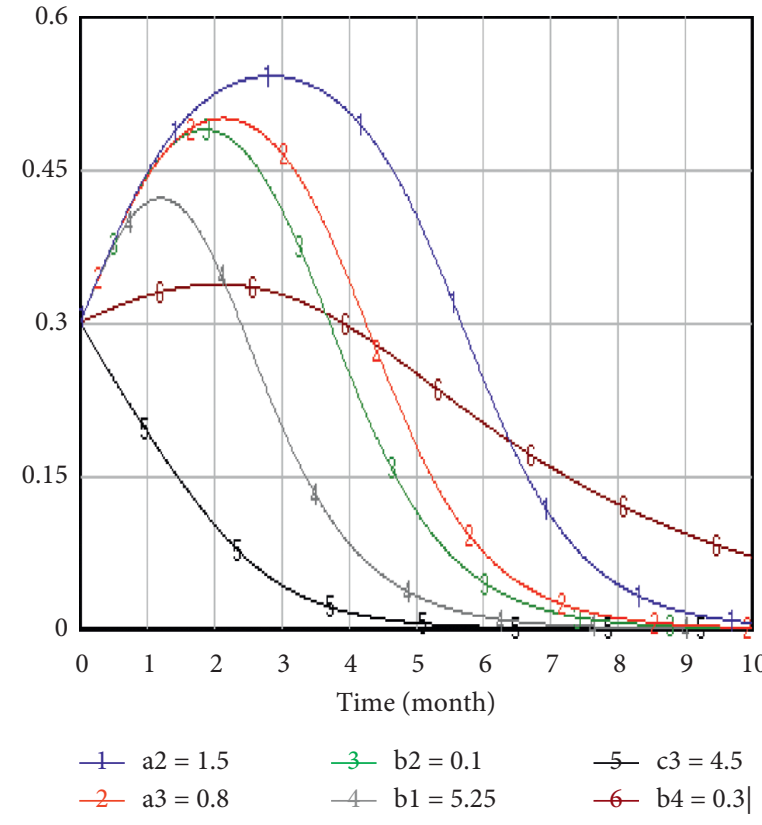

(b)

FIgURE 4: Simulation results of the local stability at point F $(1,0)$ under different conditions. (a) Construction net community $\alpha$. (b) Government encouraging $\beta$.

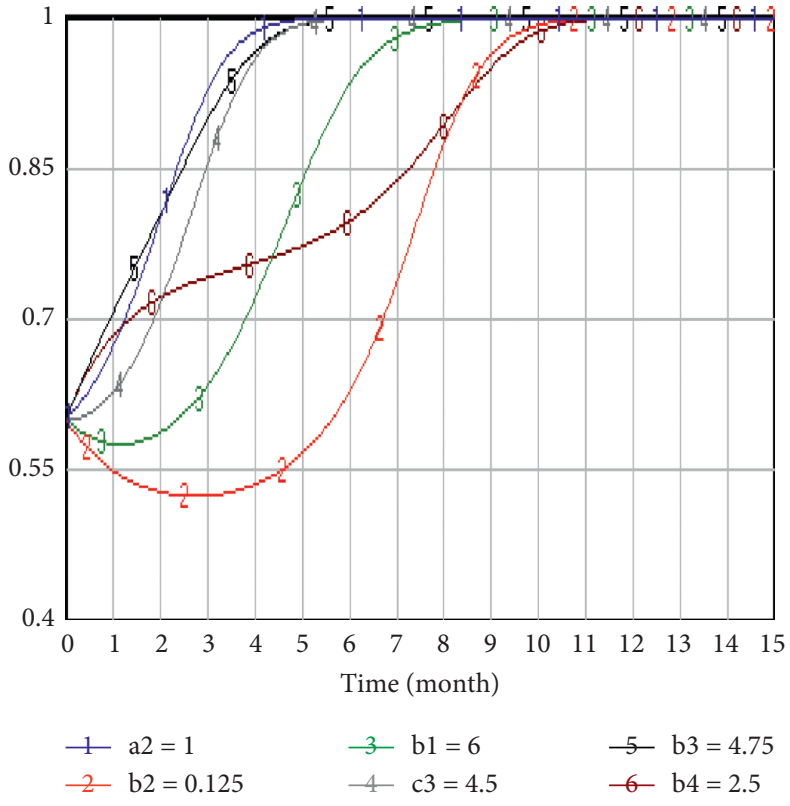

(a)

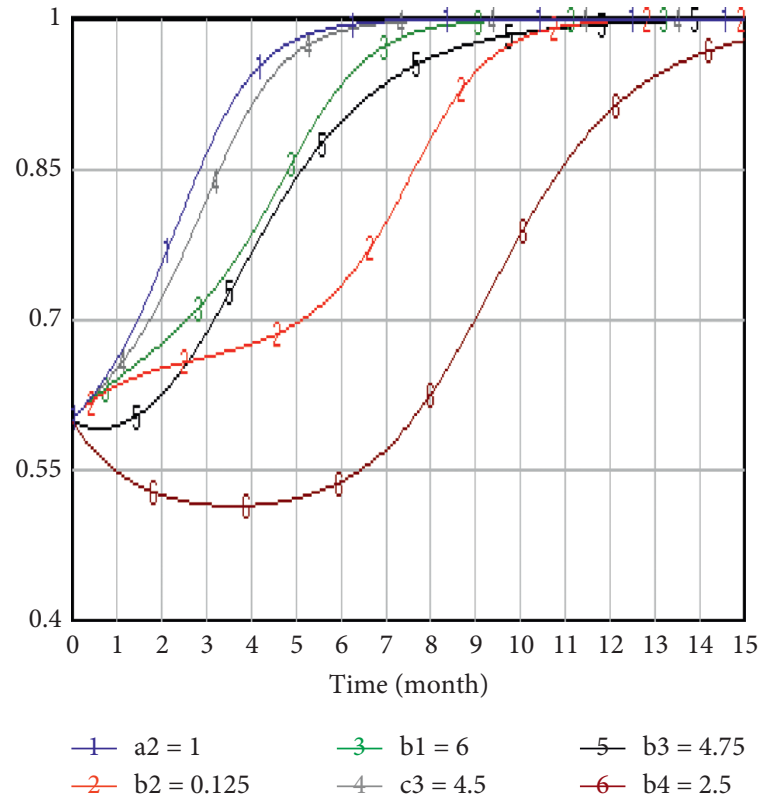

(b)

Figure 5: Simulation results of local stability at point $F(1,1)$ under different conditions. (a) Construction net community $\alpha$. (b) Government encouraging $\beta$.

\section{Conclusion}

In this study, a game based on the system dynamics and evolution using the Vensim DSS simulation software is built from the perspective of economic analysis. Network knowledge community construction requires the collaboration of multiple parties (for example, the government and investors) and continuous investment in human, economic, and technical sectors, which is a long-term decision-making process. This research can promote the possibility and 
necessity of building a network knowledge community. In addition, it also provides the operating tools of the network knowledge community which can be built by adjusting indexes $[27,28]$.

Policy Recommendation 1. The ESS can be determined at 3 equilibrium points in the system, which shows that taking the variables of this model as a prerequisite, the construction network building knowledge community has a high probability and the conditions are broad. When adjusting the variables to establish a stable path, we can test the integrity of the system's running cycle either by extending its running time or by changing the method of selecting the corresponding variables. Adjusting variable search for stable way sometimes may be extended by system operation cycle time to test the system integrity and sometimes need to adjust corresponding to the variable's way. The government and investors should increase the attribute variables as much as possible, to promote the diversity and richness of the attributes and offer more options for the mediation variables of the stability strategy.

Policy Recommendation 2. Equilibrium point $(1,1)$, with the same conditions and had the shortest evolution, is the optimal strategy point, so we should actively build positive strategic conditions to promote the construction of the network knowledge community. When one party is positive and the other is negative, the benefit matrix of both parties will be changed through the subsidy and punishment mechanism, respectively, to decrease the threshold value that affects both sides. The government should increase the subsidy and tax incentives for the enterprises that choose to invest in the construction network knowledge community and increase the weight of punishment for enterprises that are not active in the construction process. Additionally, it is necessary to strengthen the publicity of the network knowledge community and ensure that the investment and construction enterprises that decide to invest in a network knowledge community will earn a good social reputation, brand value, and corporate benefits to minimize the cost of building the network knowledge community. Moreover, the establishment of a social coordination mechanism for the development of the network knowledge community is time consuming. Thus, other equilibrium variables can be added when multiple departments adjust to the system at the same time to promote the stability of the entire system.

Simulation model is used to analyse the possibility of constructing the network knowledge community. The influence of each characteristic index in the model on the level variable is studied, and the key strategies are analysed and identified. The research of this project not only provides effective analytical methods and tools for the research on the construction of the network knowledge community, but also deepens the application of system dynamic theory and game theory in the field of economic management.

\section{Data Availability}

The authors confirm that all data underlying the findings described in this manuscript are fully available without restriction.

\section{Conflicts of Interest}

The authors declare that they have no conflicts of interest.

\section{Authors' Contributions}

Both Yu Zhenlei and Guo Chunxia conceptualized the study, were involved in formal analysis and methodology, and wrote the original draft; data curation was done by Guo Chunxia; writing-review and editing-was done by $\mathrm{Yu}$ Zhenlei.

\section{Acknowledgments}

The authors would like to thank the participants who volunteered for this study. The authors also thank Tian Wenli for data curation assistance, as well as for programming and technical support.

\section{References}

[1] L. Wang, Q. Cheng, and Y. Liu, "Library 2.0 network knowledge community construction," Intelligence Magazine, vol. 4, pp. 150-153, 2007.

[2] H. Chen and X. Cao, "Knowledge communication mechanism in library network knowledge community," Library Studies, vol. 6, pp. 10-13, 2011.

[3] L. Gao and C. Hu, "Continuous use of behavioral impact analysis by users in network knowledge community service," Modern Intelligence, vol. 1, pp. 14-17, 2014.

[4] Z. Du, H. Fu, and H. Li, "Simulation model of knowledge spread and spread in network knowledge community," J. Intelligence Theory and Practice Research, vol. 3, pp. 127133, 2019.

[5] M. Jankowski-Lorek, S. Jaroszewicz, Ł. Ostrowski, and A. Wierzbicki, "Verifying social network models of Wikipedia knowledge community," Information Sciences, vol. 339, pp. 158-174, 2016.

[6] C.-J. Chen and S.-W. Hung, "To give or to receive? factors influencing members' knowledge sharing and community promotion in professional virtual communities," Information \& Management, vol. 47, no. 4, pp. 226-236, 2010.

[7] E. H. Hwang and D. Krackhardt, "Online knowledge communities: breaking or sustaining knowledge silos," Production and Operations Management, vol. 29, no. 1, pp. 138-155, 2020.

[8] X. Liang and Y. Xiao, "Game theory for network security," IEEE Communications Surveys \& Tutorials, vol. 15, no. 1, pp. 472-486, 2013.

[9] J. J. Ahmad, S. Li, R. Thavot, and M. Mattavelli, "Secure computing with the MPEG RVC framework," Signal Processing: Image Communication, vol. 28, no. 10, pp. 1315-1334, 2013.

[10] G. Zhu and M. Feng, "Copyright protection scheme of video resources for libraries, museums and archives based on quantization modulation watermarking," New Technology of Library and Information Service, no. 10, pp. 105-111, 2016. 
[11] H. Zhang, Z. Xu, D. Zhou, and J. Cao, "Waste cooking oil-toenergy under incomplete information: identifying policy options through an evolutionary game," Applied Energy, vol. 185, pp. 547-555, 2017.

[12] X. Gao, W. Zhong, and S. Mei, "A game-theoretic analysis of information sharing and security investment for complementary firms," Journal of the Operational Research Society, vol. 65 , no. 11, pp. 1682-1691, 2014.

[13] O. Satoshi, M. Takeru, and M. Kazunari, "Co-evolutionary design of a watermark embedding scheme and an extraction algorithm for detecting replicated two-dimensional barcodes," Applied Soft Computing, vol. 46, no. 9, pp. 991-1007, 2016.

[14] M. E. Kabir, H. Wang, and E. Bertino, "A role-involved purpose-based access control model," Information Systems Frontiers, vol. 14, no. 3, pp. 809-822, 2012.

[15] C. Y. Han, B. J. Lunday, and M. J. Robbins, "A game theoretic model for the optimal location of integrated air defense system missile batteries," Informs Journal on Computing, vol. 28 , no. 3, pp. 405-416, 2016.

[16] X. Deng, D. Han, J. Dezert, Y. Deng, and Y. Shyr, "Evidence combination from an evolutionary game theory perspective," IEEE Transactions on Cybernetics, vol. 46, no. 9, pp. 20702082, 2016.

[17] C. S. Gokhale and A. Traulsen, "Evolutionary multiplayer games," Dynamic Games and Applications, vol. 4, no. 4, pp. 468-488, 2014.

[18] P. D. Taylor and L. B. Jonker, "Evolutionary stable strategies and game dynamics," Mathematical Biosciences, vol. 40, no. 12, pp. 145-156, 1978.

[19] J. Maynard Smith, "The theory of games and the evolution of animal conflicts," Journal of Theoretical Biology, vol. 47, no. 1, pp. 209-221, 1974.

[20] J. M. Smith and G. R. Price, "The logic of animal conflict," Nature, vol. 246, no. 5427, pp. 15-18, 1973.

[21] H. Cavusoglu, B. Mishra, and S. Raghunathan, "A model for evaluating IT security investments," Communications of the ACM, vol. 47, no. 7, pp. 87-92, 2004.

[22] S. Du, X. Li, J. Du, and H. Zhu, "An attack-and-defence game for security assessment in vehicular ad hoc networks," Peer-to-Peer Networking and Applications, vol. 7, no. 3, pp. 215-228, 2014.

[23] L. A. Gordon, M. P. Loeb, and W. Lucyshyn, "Sharing information on computer systems security: an economic analysis," Journal of Accounting and Public Policy, vol. 22, no. 6, pp. 461-485, 2003.

[24] D. Friedman, "On economic applications of evolutionary game theory," Journal of Evolutionary Economics, vol. 8, no. 1, pp. 15-43, 1998.

[25] R. Zhao, G. Neighbour, J. Han, M. McGuire, and P. Deutz, "Using game theory to describe strategy selection for environmental risk and carbon emissions reduction in the green supply chain," Journal of Loss Prevention in the Process Industries, vol. 25, no. 6, pp. 927-936, 2012.

[26] Y. Tian, K. Govindan, and Q. Zhu, “A system dynamics model based on evolutionary game theory for green supply chain management diffusion among Chinese manufacturers," Journal of Cleaner Production, vol. 80, pp. 96-105, 2014.

[27] J. Cheng, "Analyzing the factors influencing the choice of the government on leasing different types of land uses: evidence from Shanghai of China," Land Use Policy, vol. 90, Article ID 104303, 2020.

[28] J. Cheng, "Data analysis of the factors influencing the industrial land leasing in Shanghai based on mathematical models," Mathematical Problems in Engineering, vol. 2020, Article ID 9346863, 11 pages, 2020. 